\title{
An Experiential Approach to the Design and Evaluation of a Gamified Research Tool for Law in Children's Lives
}

\author{
Effie Lai-Chong Law \\ University of Leicester \\ Leicester, UK \\ 1c19@le.ac.uk
}

\author{
Dawn E. Watkins \\ University of Leicester \\ Leicester, UK \\ dew3@le.ac.uk
}

\author{
Joanna P.L. Barwick \\ University of Leicester \\ Leicester, UK \\ jplb1@le.ac.uk
}

\author{
Elee S. Kirk \\ University of Leicester \\ Leicester, UK \\ ek170@le.ac.uk
}

\begin{abstract}
The aim of the project Law in Children's Lives is to gamify the research activity of collecting data with a digital game to assess children's awareness of law in their everyday lives. Our main research goal is to address the theoretical and practical concerns in gamification through a user(child)centred experiential approach. We grounded the design and evaluation of the game in the established User Experience (UX) theoretical frameworks - Hassenzahl's hedonicpragmatic model and McCarthy \& Wright's four threads of experience. The game prototype consists of four microworlds with each comprising a set of scenarios where children are asked to select an action option and record their reasons by talking to the non-player character. The game was evaluated with 634 children aged 7-11 years. The levels of perceived fun, interestingness and ease of playing were generally high. The game could stimulate the children to think about the given scenarios and beyond them.
\end{abstract}

\section{Author Keywords}

Gamification; Children; Law; User Experience; Theories

\section{ACM Classification Keywords}

H.5.m. Information interfaces and presentation (e.g., HCI): Miscellaneous;

\section{INTRODUCTION}

The prevailing ludic culture has contributed to the burgeoning trend of gamification [1], which can be generally defined as "the use of game design elements in non-game contexts" [2] or more specifically as "using game-based mechanics, aesthetics and game thinking to engage people, motivate action, promote learning and solve problems" [3]. The latter resonates with the holistic view of User Experience (UX) that encompasses both the hedonic and pragmatic aspect of interacting with technologies [4]. Experience design [5, 6], with its tenet of designing interactive products that evoke pleasurable and meaningful

Permission to make digital or hard copies of all or part of this work for personal or classroom use is granted without fee provided that copies are not made or distributed for profit or commercial advantage and that copies bear this notice and the full citation on the first page. Copyrights for components of this work owned by others than ACM must be honored. Abstracting with credit is permitted. To copy otherwise, or republish, to post on servers or to redistribute to lists, requires prior specific permission and/or a fee. Request permissions from Permissions@acm.org.

IDC '16, June 21-24, 2016, Manchester, United Kingdom

(C) 2016 ACM. ISBN 978-1-4503-4313-8/16/06 ...\$15.00

DOI: http://dx.doi.org/10.1145/2930674.2930722 experiences in users, is particularly relevant to the design of gamified tools in a variety of contexts.

Gamification can be applied to a broad range of human activity such as learning [7], health self-tracking [8], environmental sustainability [9], business management [10], and academic research [11]. Apparently, the desirable effect of gamification may work particularly well if the mediating artefact is digital games (cf. physical toys) [1] and if the target group is children. Nowadays most children are familiar with computer technology in general and digital games in particular, which, when well-designed, can sustain their attention, curiosity and co-operation in dealing with given tasks or quests [12].

Indeed, gamifying learning in the form of digital educational games for children is an endeavor that has already attracted a number of research studies in last decades (e.g., $[13,14$, 15]). In contrast, gamifying research with children is a more recent research effort [16]. A gamified research tool is to utilize the motivational power of digital games to facilitate a research activity, be it collecting data, analysing data or presenting results (or even the whole chain of activity). While both gamified learning and gamified research have been applied in various domains, they are more prevalent in science and technology (e.g., [17, 18, 19]) than in other disciplines such as law. Our project, Law in Children's Lives (LICL), has ventured into this new area by creating a gamified research tool to investigate a significant topic with high societal impact.

LICL is an 18-month research project aiming to exploit the potential of gamification to research with school children aged 8 to 11 years old. The research method commonly used to develop a deep understanding of children's awareness of a particular topic is semi-structured interview, with or without the use of props (e.g., pictorial scenarios). However, there are some known issues of this conventional approach, which is: (a) time-consuming, especially when interviews are conducted on a one-to-one basis; (b) difficult to engage children in imagining scenarios vividly and responding accordingly; (c) prone to the social desirability (or experimenter) effect [20]. We argue that a gamified research tool instantiated as a digital game can resolve the issues (a) and (b) while mitigating (c). First, a large number of children can participate in a gamified computer-based research activity simultaneously; the size of an experimental session is primarily limited by the number of computers available at 
the same time. Second, high interactivity and quality audiovisual effects afforded by multimedia technologies enable children to immerse in a game micro-world, evoking their thoughts and emotions relevant to a given scenario therein. Third, a gamified research activity can be guided by a child-friendly non-player character (NPC) in the game which children perceive as a peer rather than as an authority figure (e.g., an experimenter) whom children may tend to please or feel anxious about.

The main goal of the LICL project is twofold: to examine children's awareness of certain legal provisions that apply to them, and to assess children's perception of their being empowered by these laws in their everyday lives. The earlier related work has looked into these issues but rather from a law-first approach [21], assessing the level of children's understanding of legal institutions and processes [22, 23] and the role of legal actors [24].

In LICL we adopt a child-centred approach to explore how far children demonstrate legal competence in their decisionmaking. The gamification part is the development of an Android tablet-based game entitled"Adventures with Lex" for data collection. Based on the findings of the participatory design activities, four settings with which children are most familiar have been identified - School, Shop, Park, and Friend's home - as micro-worlds of the game. In each of these micro-worlds, several scenarios are presented where children are expected to apply their legal competence to interpret the situations and select an action out of the given options accordingly. Through simple dialogues between a child and an alien, Lex (NPC), in the game, the child is elicited to describe the rationale underlying her or his choice of action. The dialogues are recorded by the game. While the dialogical data are rich for us to infer the children's legal competence, this is not the scope of this paper to report on the related findings as it entails an independent elaborate exposition.

Our main research goal is to address the theoretical and practical concerns in gamification through a user(child)centred experiential approach. Apart from the definitional issue that the area of gamification is facing [1], another critical issue is the lack of theoretical grounding. We aim to bridge this gap by integrating UX theories and gamification practices. By describing the processes and challenges associated with the design of the game features and with the evaluation of the game prototypes, we aim to enable other researchers to adapt our approaches for their own work. This can also contribute to a rather limited body of applied knowledge of gamification, thereby advancing this emerging area.

\section{RELATED WORK}

Three strands of research are relevant to our experiential approach: Participatory Design, UX frameworks, and Serious Games. In reviewing the related concepts in the literature, we delineate how they have informed the work in our project LICL.

\section{Participatory Design (PD)}

Participatory design (PD) is the approach that aims to involve stakeholders, including typically users and the development team, actively on an ongoing basis to co-design a product to ensure that it will meet users' needs and preferences and that it will be accepted and adopted [25]. PD is increasingly employed for designing technology for children [26,27,28,29]. Based on the assumption that children can contribute their own ideas to creative design [26], they are involved as informants, testers, end-users and cooperative inquirer throughout the entire design process [28]. Children are enabled to develop a narrative version of a game before it is implemented digitally [27] and to evaluate and redesign game prototypes iteratively with the game design and development team [29].

The development of Adventures with Lex was an inter-sector collaboration between an academic research team and a game company. The former comprises a domain-specific expert (lawyer) and other academics experienced in research with children and on games whereas the latter offers expertise in graphics design and in other technical implementations.

In following the PD approach, the researchers worked with the prospective end-users of the game - children of relevant ages - for co-designing the main game elements, including the game characters, the micro-worlds, and the reward mechanism. The ongoing involvement of children in the game design from the outset of the project aligned with its underpinning philosophy that children's voices must be heard. Specifically, the PD technique we employed was focus groups [30], which involved two focus groups of children aged 7-11 years old from three different primary schools. Two researchers moderated a focus group with 8 to 10 children, who were asked to share their experiences of using technology, their familiarity with different games and platforms, their criteria for a good game, their mundane activities and the level of independence they typically have for undertaking such activities. The data so gathered were relevant to the initial instantiation of the game elements. In the subsequent cycles of evaluation and redesign of the game prototypes, the children of the focus groups continued their contribution through their comments and improvement suggestions. Overall, the children's voices have informed the decision processes throughout the development of the game from its earliest to the latest version.

\section{UX Frameworks for Experience (-centred) Design}

User Experience (UX) as a field of study is an extension of usability to focus on people's emotions and needs in connection to their use of interactive systems [31]. Since the turn of millennium a number of theoretical frameworks in UX have been developed (for review see [32]), which have not only enhanced our understanding of the phenomena related to what we empirically call "experience" but also informed the practice of interaction design. Among them, Hassenzahl's hedonic-pragmatic model [4] and McCarthy \& 
Wright's sense-making in experience [6] are most referenced [32]. In the following we summarise the main ideas of the two frameworks.

According to Hassenzahl [4], when individuals encounter a product, they perceive its features and thereby construct a preliminary personal evaluation of the product quality comprising sets of pragmatic and hedonic attributes Different consequences are resulted from this initial perceived product quality: cognitive consequences in terms of judging the product appeal (e.g. goodness), emotional consequences (e.g. pleasure), and behavioural consequences (e.g. continued use).

McCarthy and Wright's framework [6] is integrated with the four threads of experience. The sensual is concerned with our bodily engagement with a situation, characterized as visceral experience. The emotional involves ascribing importance to other objects with respect to a person's (or her social others') needs and desires. The spatio-temporal refers to the time and place where an experience is located. The compositional is concerned with the narrative structure of an experience.

We describe how the key concepts of the two frameworks have been translated into the design of the game Adventures with Lex. In accord with Hassenzahl's model, the pragmatic attributes of the game are related to the children's need to attain the behavioural goals of exploring the micro-worlds and responding to the questions therein. The game should offer effective and efficient ways to achieve the goals by providing the required functionalities (e.g., the audiorecording facility) and the ease of using them. On the other hand, the hedonic attributes of the game are related to stimulation, identification and evocation, albeit to different extents. By stimulation, it implies that the novel and challenging characteristics of the game can afford the development of knowledge and skill, which is the human need of competence [4] (cf. the holistic view of UX). In the game, the children are stimulated to think about questions about different real-life situations with most of them having no definite right or wrong answers. They have to exercise their decision-making ability and reason their choices. Identification is related to the human basic need of social relatedness by expressing one's self through objects. Wearing a headset and talking to it may alter the children's self-image positively [33]; this self-presentational function is essentially social as people care how they are seen by others. Evocation implies that the game may be reminiscent of the children's past events, which can evoke both positive and negative emotions. Together the three hedonic attributes can account for the children's pleasurable and meaningful experiences in playing the game, which can engage and motivate them to respond to the questions.

The sensual aspect of experience, in light of McCarthy and Wright's framework, is related to a rapid judgment of the aesthetic quality of an object, though through a deeper cognitive evaluation or an actual interaction with the object the initial impression can be adjusted shortly after it is formed. In case of Adventures with Lex, the look-and-feel of the tablet encased in a green holder and the glossy touchbased screen can convey the sense of trendiness in the children and thus increase their enthusiasm for the game. The emotional aspect of the game is manifest as the pseudodialogues between the children and Lex's whose utterances are scripted. Nonetheless, this social element is considered crucial for the positive user experience. The space of the experience is defined by the four virtual micro-worlds occupied by objects whose dynamicity, as static images, is limited whereas the time is left undefined, leaving room for the children to imagine. The compositional aspect of experience is instantiated as the two-layered narrative with the higher-level context being Lex's alien world of which limited information is portrayed lest it would distract the children from the scenarios. The lower-level contexts are manifest as the four micro-worlds where the gaps of narratives (e.g., why a kid got smacked by his mother in the Park) are to be filled in by the children, stimulating them to compose narratives with coherent reasoning.

\section{Serious games and game elements}

One strong argument for using digital games to assess children's awareness of law in their everyday lives is that games do not exist in a vacuum [34]. In playing a game, especially when it is set in a real-life context, players bring their own personal experiences in making sense of the relations of the objects in the game world (cf. the evocative aspect of Hassenzahl's [4]; Calleja [35]). Similarly, Salen and Zimmerman [36] observe that games are a reflection of the players who play them. These arguments lend support to the use of gamification in our project LICL.

According to [1], gamification is the most recent and visible instantiation of the interpenetration of games and everyday lives. However, this new area is troubled by criticisms (e.g., [37]) and terminological confusions with the related notions such as serious games. A unified definition of serious games is yet to be derived (e.g., $[38,39,40])$, but they are generally defined as games that serve certain purposes (e.g., learning) other than pure entertainment. Some researchers argue that serious games and gamification are essentially the same as they both aim to motivate people and promote learning (or solve problems) using game-based thinking and techniques [3]. In contrast, some researchers attempt to differentiate them by arguing that serious games are full-fledged games whereas gamification uses a selection of design elements from games to afford gameful experiences [1]. We assume the nuances between the two notions.

\section{GAME DESIGN}

By integrating the concepts reviewed above with the Game Elements-Attributes Model (GEAM) [41], which summarises the main game features based on the extensive literature review, we list the game elements (i.e., abstract building blocks that form the fundamental architecture of every game) and the instantiation of associated game attributes in Adventures with Lex (Table 1). 


\begin{tabular}{|l|l|}
\hline $\begin{array}{l}\text { Game } \\
\text { element* }\end{array}$ & Instantiation of game attributes \\
\hline $\begin{array}{l}\text { Setting/ } \\
\text { World }\end{array}$ & $\begin{array}{l}\text { The objects and the environment of the game } \\
\text { are 2D cartoons representing real-life items. }\end{array}$ \\
\hline $\begin{array}{l}\text { Input/ } \\
\text { output }\end{array}$ & $\begin{array}{l}\text { Tablet-based touchscreen; a headset for } \\
\text { audio input/output. }\end{array}$ \\
\hline Player & Playing on an individual basis; \\
\hline Perspective & $\begin{array}{l}\text { Bound to character of the game; the first- or } \\
\text { third-person perspective, depending on the } \\
\text { scenario }\end{array}$ \\
\hline Actions & $\begin{array}{l}\text { Spinning a virtual wheel to land in a micro- } \\
\text { world randomly; Responding orally to the } \\
\text { questions embedded in the scenarios of the } \\
\text { micro-worlds as part of pseudo-dialogues } \\
\text { with the game character }\end{array}$ \\
\hline Challenges & $\begin{array}{l}\text { Decision-making on choosing one of the } \\
\text { given options for a scenario and justifying } \\
\text { the choice by speaking out to the non-player } \\
\text { character. }\end{array}$ \\
\hline Goals & $\begin{array}{l}\text { The goal given is to complete the scenarios } \\
\text { of the micro-worlds and to build one's own } \\
\text { alien pet. }\end{array}$ \\
\hline Rewards & $\begin{array}{l}\text { Building an alien pet; upon completion of a } \\
\text { micro-world, one is granted the right to visit } \\
\text { the Alien Pet Lab where one can select body } \\
\text { parts; one body part is unlocked when a } \\
\text { micro-world is done. }\end{array}$ \\
\hline Structure & $\begin{array}{l}\text { The four micro-worlds are disjoint parts } \\
\text { linked up with a small background story that } \\
\text { a naïve alien wants to know more about the } \\
\text { Earth. }\end{array}$ \\
\hline
\end{tabular}

*Games are rule-based; rules are the overarching game element.

Table 1. Instantiation of the game elements

The four micro-worlds - Park, School, Shop and Friend's home - were selected based on the data of the participatory design activities described above. They were identified as places that children in this age group might sometimes visit without being accompanied by their parent or caregiver. To control the order effect, the micro-world is selected randomly through a virtual spinning wheel (Figure 1) that serves as a navigation tool.

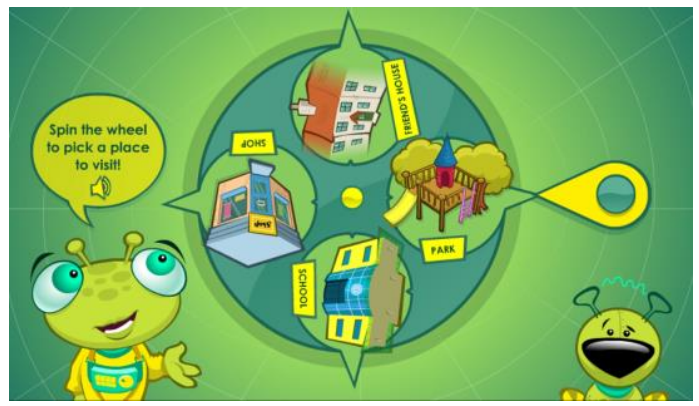

Figure 1. A virtual spinning wheel as a navigation tool

In each micro-world, the children are presented with different scenarios and asked some related questions. To ensure the accessibility, the questions were presented in both textual and audio format; by clicking a loudspeaker icon the children can listen to the questions read out loud by Lex. Upon choosing an option, the children are asked to explain their choice in response to Lex's prompt "Why do you think that?"

To illustrate different types of question (Q) and answer (A) in the scenarios, we depict one scenario per micro-world. Over the 13 scenarios in 4 micro-worlds, there are altogether 20 questions (excluding Lex's prompt) and three answer formats: multiple categorization (e.g., the answer option for Physical chastisement, Figure 2b, and for Sword fight with rulers, Figure 3b), slider (e.g. the answer option for Home alone, Figure 4b), and multiple choice (e.g. the answer option for Snail in bottle, Figure 5b). All the Qs and As were iteratively co-developed by the research team with child psychologists (i.e. advisory board members of the project) and more importantly, with the children participating in the participatory design activities, using the paper-prototyping and focus group techniques. This was to ensure that the language used is appropriate for their ages (7-11 years) and that the formats are understandable (i.e., drag-and-drop, categorical scales, slider).

\section{Park: Physical chastisement}

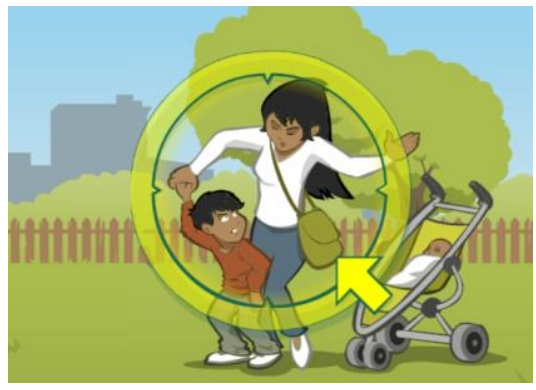

Figure 2a. The game scenario of physical chastisement

$Q$ : Are any of these people allowed to hit children?

$A$ : Six options are: Parents, Adult relatives, Children, Police, Neighbours, and Teachers. To indicate if a person is allowed/not allowed, her/his head is dragged to the 'Yes'/ 'No' test-tube, and in case of undecided, to 'Don't know'

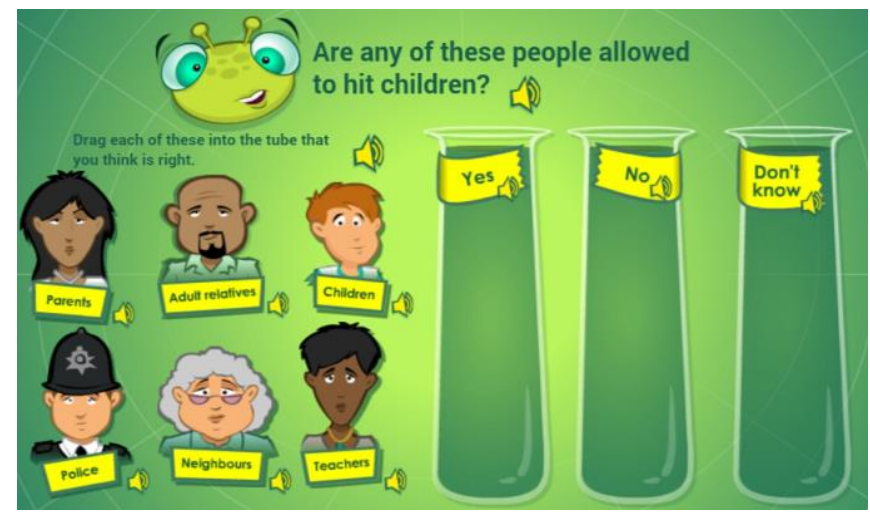

Figure 2b. Multiple categorization answer format with the drag-and-drop mechanism 
School: Sword fighting with rulers

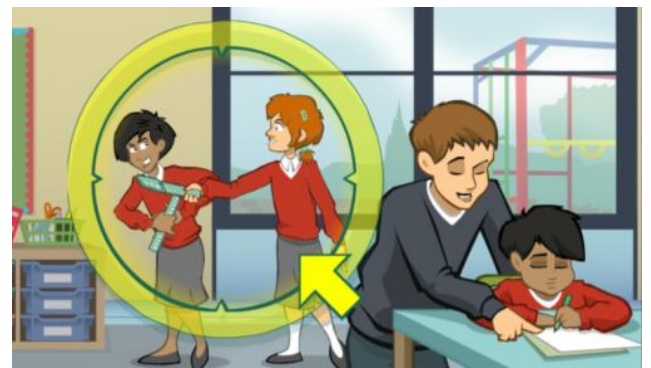

Figure 3a. The game scenario of sword fighting with rulers

$Q$ : Two girls were sword-fighting with plastic rulers in their classroom. One of them was injured as a piece of the plastic snapped off into her eye. Who is responsible for this?

$\boldsymbol{A}$ : The child who was hurt; The child who was not hurt; The teacher; The head teacher; The school governors; The local council. To indicate if each of six persons is thought to be responsible, one drags the sticker "Yes", "No" or "Don't know" onto the respective figure.

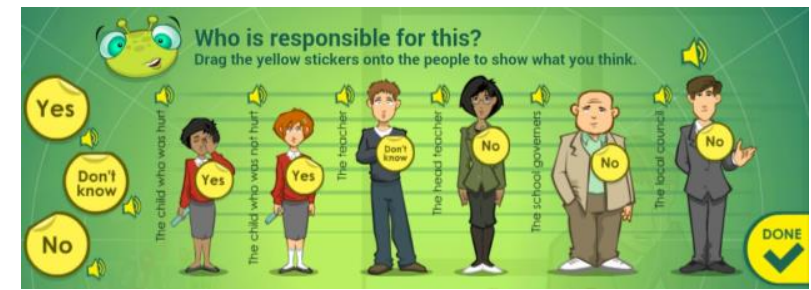

Figure 3b. Multiple categorization answer format

\section{Friend's home: Home alone}

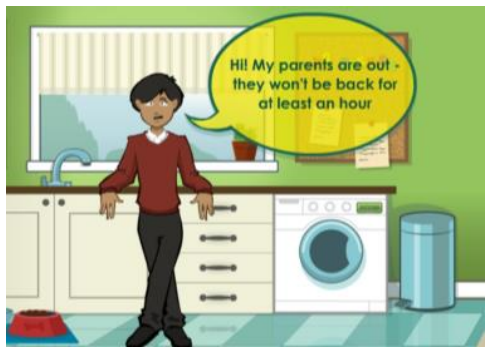

Figure 4a. The game scenario of home alone

$Q$ : Friend welcomes the child, "Come in! My parents are out - they won't be back for at least one hour". At what age can you be left at home on your own?

$A$ : A slider with integers from $0-18$ is given

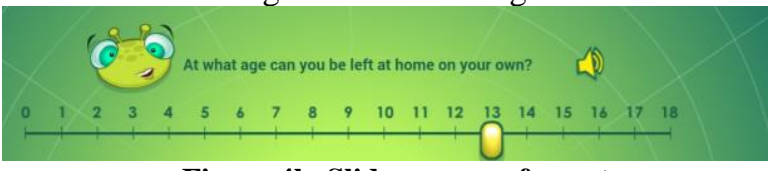

Figure 4b. Slider answer format

Shop: Snail in bottle

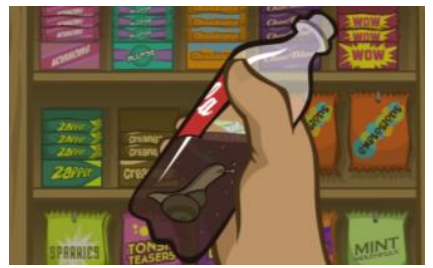

Figure 5a. The game scenario of snail in bottle
$Q$ : The child discovers a dead snail in the drink bottle. What can you do about that?

A: The five options (Ask for money back; Ask for a new one; Nothing - throw it in the bin; Ask a friend for help; Go home and ask for help) are presented as buttons to click on.

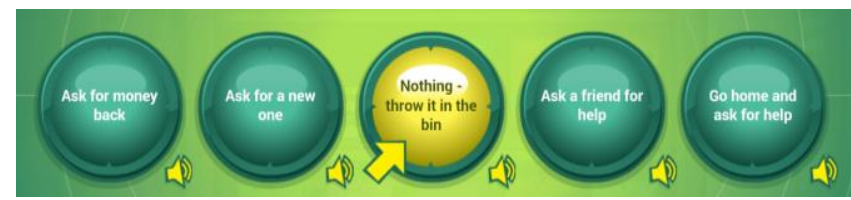

Figure 5b. Multiple choice answer format

\section{EMPIRICAL STUDIES \\ Pilot Study}

In addition to the iterative PD activities with the children in the form of focus groups, the beta-version of the game was pilot tested with two groups in two different schools, 35 children aged 8-9 years and 31 children aged 9-10, testing the procedure to be used for the main study. After playing the game, they were asked to feed back their likes and dislikes about the game by completing a "postcard". The two game features - speaking into the tablet as an interaction modality; building the alien pet as a reward - were explicitly mentioned by $44 \%$ and $72 \%$ of the children as their likes.

\section{Reflection on the Game Design Process}

Based on the data of the Pilot Study, several issues were identified: (i) the lack of the facility to undo the choice made when the children accidentally clicked the wrong button or intentionally changed their mind; (ii) misleading game visuals; the two girls in the sword fighting with rulers scenario were supposed to be engaged in fun playing, but they were portrayed as if one (with an aggressive look) was bullying the other (with a defensive look). The interpretation of the scenario would then be distorted; (iii) the awkward format of raw data to be automatically captured as the data file of the game. Prior to the main study, (i) and (iii) were addressed, but (ii) was not changed due to cost.

These technical issues led us to reflect on the importance of clear and ongoing communications for bridging the gap between the conceptual design and graphical design. The difference between the teams in understanding the role of the two characters in the sword-fighting scenario would be difficult to identify in the conceptualization phase, especially when the teams were distributed in two physical locations. Only when the prototype with tangible graphics was available for inspection then the consequence of the misunderstanding emerged. Hence, it is critical to leave enough buffer time for negotiating and fixing such issues. This was proved particularly challenging for a short-term project like LICL.

\section{Main Study \\ Participants}

As mentioned, players bring in their own lived experiences of real-life social and personal relations into a virtual game world [34]. Hence, it is logical to assume that demographic variables such as age, gender and socioeconomic status can 
influence the way how children respond to the scenarios of the game. However, socioeconomic status could be too privacy-sensitive to be collected at the individual level. Alternatively, such data can be obtained at the group level, which, in our case, is the school level. Based on the Income Deprivation affecting Children Index (IDACI) ${ }^{1}$ a school can be categorized as a high, medium or low deprivation level. Thanks to the East Midlands Widening Participation Research and Evaluation Partnership providing access to this data, we selected six schools from each of the three deprivation levels. Eight of the 18 schools accepted the invitation to take part. While children were asked to give their own consent, only those whose parental/carer's returned a complete consent were allowed to participate, and the return rate ranged from $50 \%$ to $95 \%$. Two of the schools involved three year groups (Year 4, 5, 6) whereas the other six involved two of these year groups. In a period of two months (June-July 2015) when the eight schools were visited, data of altogether 634 children aged 7-11 were collected. This would not have been possible if the digital game had not been used.

\section{Procedure}

The game sessions were conducted on a class basis with an average size of about 30 children. Usually three to four researchers attended each session to distribute and collect the testing materials, deliver instructions, provide help and observe the children's gameplay behaviours. One or two teachers were also present to assist local matters such as rearranging classroom furniture and seating. The following six steps were carried out in one session lasting one hour:

Step 1:Researchers distributed the equipment - tablets and headsets - and identification code (we called it 'Cosmic Code' to make it more interesting for the children), which was used for data anonymization;

Step 2:Researchers presented a brief introduction about the project and demonstrated how the equipment worked

Step 3:Children were asked to enter the code into the tablet and play the game on their own pace till its end (no time limit was imposed);

Step 4:Children were asked to put up their hand when they finished the game. They were then given a paperbased evaluation questionnaire to fill in. Children who finished before the others in the group were given activity sheets on colouring and word search;

Step 5:Researchers debriefed the children about certain issues of the scenarios that might be perceived as sensitive for some children.

Step 6:Children were given the opportunity to ask questions and give feedback on any aspect of the game session, and were also advised to discuss any concerns about the issues raised in the game with an adult whom they trusted;

\footnotetext{
1 https://www.gov.uk/government/uploads/system/uploads/attach ment_data/file/6871/1871208.pdf
}

Step 1 and Step 2 each takes $\sim 5$ minutes; Step 3 takes $~ 20$ minutes, varying with individual children; Step 4 takes $\sim 10$ minutes, Step 5 and Step 6 together $\sim 15$ minutes.

\section{GAME EVALUATION}

We developed and printed the evaluation questionnaire on paper instead of integrating it into the game. The main reason was to ensure that the children would differentiate the evaluation questions, which focused on the user experience of the game, from those in-game law-related questions. The change of the medium, from the digital to paper-based, could help the children be aware of the differences. A drawback of this approach was the time-consuming process of digitizing the data for analysis.

\section{Methods}

Questionnaire design

The two UX frameworks - Hassenzahl's [4] and McCarthy \& Wright's [6] - delineated above have not only informed the design but also the evaluation of the game from the user experience perspective. In accord with the experiential perspective, we aimed to understand whether the children perceived the game to be usable, pleasurable, attractive, stimulating and desirable. However, two major constraints needed to be considered [42] in translating the attributes of the frameworks into the items of the questionnaire: (i) the children's language ability, which varies substantially within as well as across the age groups; (ii) the children's motivation and cognition in completing as well as understanding the items of the questionnaire.

The implications were that the language used should be simple and child-friendly, and the number of questions should be small. Hence, we used two experiential words fun (pleasurable) and interesting (attractive) - that were frequently used by the children in the focus groups when referring to criteria for a good game. Further, the quality 'usable' is referred to as 'easy'; while it tends to simplify the notion of usability, it is graspable for children. One hedonic attribute, as argued by Hassenzahl [4], is stimulation. We aimed to know whether the children were stimulated to think more about the issues addressed in the scenarios and even beyond them. The free-text format 'speech bubble' is given for the children to complete the sentence "Visiting the <micro-world> made me want to find out more about...". In addition, we evaluated the children's perception of the five game features: Lex (a friendly alien) and Rex (Lex's alien pet) were aimed to enhance emotional (social) experiences of the children in playing the game. Building an alien pet is a reward mechanism. Spinning the wheel can be a source of fun (pleasant surprise) as well as a source of frustration (taking the control away from the children). Similarly, recording one's voice can be a source of pleasurable experiences for some children but can also be anxietyinducing for others. 
In addressing the language issue, as a non-verbal alternative to text-based (Likert) scales, we adopted a visual analogue scale (VAS), which was found applicable to children aged 7 years and above [43]. Specifically, we adapted the VAS from FunToolkit [44] of which the smiley faces were co-designed with children, but we did not use the verbal labels. VAS has been widely used with children to rate their perceived level of pain. Nonetheless, there are debates whether a VAS should be labelled fully (i.e., each of the pictorial symbols has a verbal descriptor) or bipolar (i.e., each of the two end points has a verbal descriptor) or none [43]. With the ubiquitous use of smiley faces in everyday lives (e.g., social media, public facilities), it is reasonable to assume that children of aged 7-11 are familiar with the implications of different shapes of the smileys' mouths, exempting the need of textual labels. In fact, the use of verbal descriptors might undermine the purpose of using non-verbal representations to mitigate the language issue. While we did not systematically test the effect of with/without the labels of the VAS as this would be beyond the scope of this project, the qualitative responses suggested that the children clearly understood the implications of the smiley faces (see below).

In addressing the motivation and cognition issue, we followed the principle of aesthetics and minimalist design. Specifically, we attempted to make the layout aesthetically attractive to sustain the children's attention, to keep the content simple and easy to understand, and to support the retrieval of the related experience from memory by presenting a panorama view of the scenarios of the microworld (Figure 6; the same layout with different panoramas for different micro-worlds) and a visual of each of five game features to be evaluated (Figure 7).

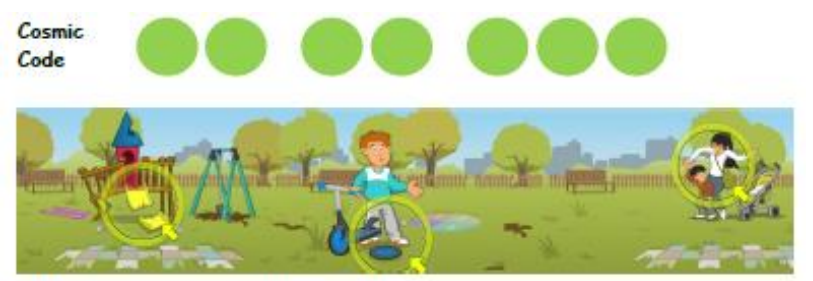

How much was this world...

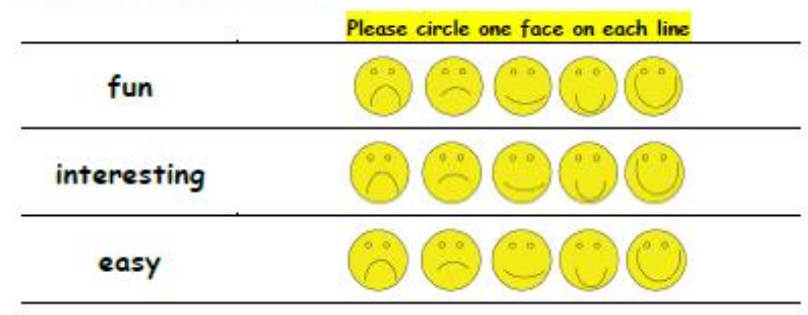

Visiting the Park made me want to find out more about...

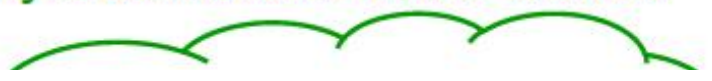

Figure 6. The evaluation items for the micro-world Park: The panorama view of the three scenarios at the top, the three scales in the middle, and a speech bubble (the lower part was cropped) for free-text format qualitative responses.
Pilot study

The preliminary version of the questionnaire was tested in the same pilot study where the initial game prototype was evaluated (see above). One significant observation was that about $1 / 4$ of the children circled only one of the three scales for each of the four micro-worlds because of the misleading instruction "Please circle one", which was then rephrased as "Please circle one face on each line" (Figure 6). However, the problem was not observed for the five game features where the same scale was used; nevertheless, we put in a new phrase "Circle one face on each line" (Figure 7). Furthermore, in distributing the questionnaire to individual children, the researcher pointed out to them that they were expected to consider all three aspects.

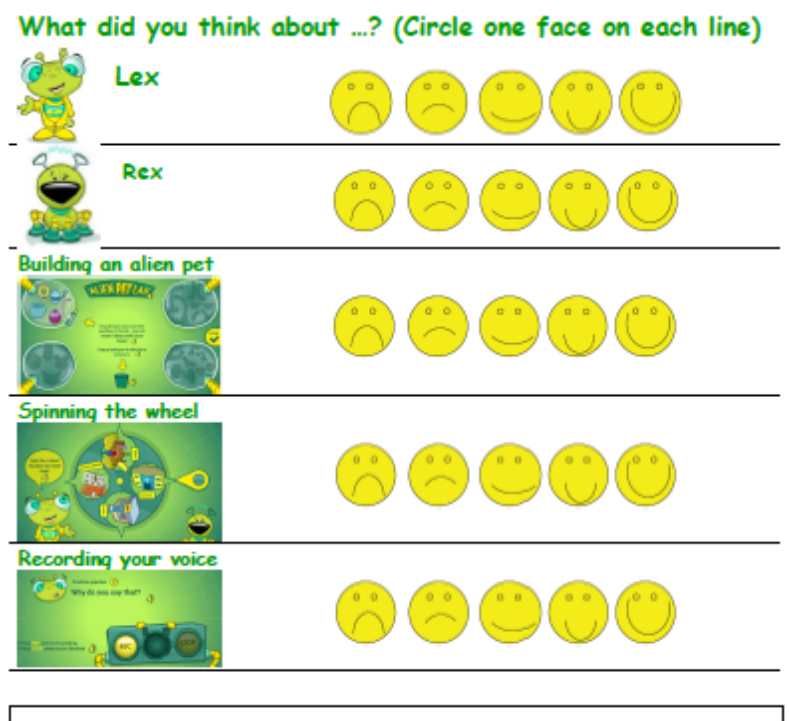

Write or draw in this box anything about the game..

Figure 7. The evaluation of five game features.

Participants

The majority of the children $(\mathrm{N}=626)$ who played the game completed the evaluation questionnaire (Table 2). However, eight did not do so because they left the respective sessions earlier, given their other obligations.

\begin{tabular}{|c|c|c|c|c|c|c|c|c|c|}
\hline \multirow{2}{*}{$\begin{array}{l}\text { School } \\
\text { Year }\end{array}$} & \multicolumn{2}{|c|}{ S-1 } & \multicolumn{2}{|c|}{ S-2 } & \multicolumn{3}{|c|}{ S-3 } & \multicolumn{2}{|c|}{ S-4 } \\
\hline & $\mathrm{Y} 4$ & Y5 & Y5 & Y6 & $\mathrm{Y} 4$ & Y5 & Y6 & Y4 & Y5 \\
\hline Boy & 16 & 18 & 27 & 20 & 14 & 19 & 22 & 23 & 14 \\
\hline Girl & 23 & 14 & 29 & 25 & 13 & 20 & 13 & 20 & 20 \\
\hline Total & \multicolumn{2}{|c|}{71} & \multicolumn{2}{|c|}{$102 *$} & \multicolumn{3}{|c|}{101} & \multicolumn{2}{|c|}{$78 *$} \\
\hline \multirow{2}{*}{$\begin{array}{c}\text { School } \\
\text { Year }\end{array}$} & \multicolumn{2}{|c|}{ S-5 } & \multicolumn{3}{|c|}{ S-6 } & \multicolumn{2}{|c|}{ S-7 } & \multicolumn{2}{|c|}{ S-8 } \\
\hline & Y4 & Y5 & Y4 & Y5 & Y6 & Y4 & Y5 & Y4 & Y5 \\
\hline Boy & 17 & 9 & 10 & 11 & 16 & 16 & 16 & 11 & 14 \\
\hline Girl & 17 & 11 & 13 & 12 & 10 & 18 & 25 & 18 & 30 \\
\hline Total & \multicolumn{2}{|c|}{54} & \multicolumn{3}{|c|}{72} & & & \multicolumn{2}{|c|}{73} \\
\hline
\end{tabular}

Table 2. Number of children by School (S), Year (Y) and Gender (*1 missing data)

\section{Results}

We report the findings of the four micro-worlds and the five game features in two sub-sections below.

Four micro-worlds: Quantitative findings 
As shown in Table 3, in general the children perceived that all the four micro-worlds were fun, interesting and easy to play, although the interestingness of Park being the lowest. It might be attributed to a rather challenging question "Are people allowed to hit children?", which is connected to the scenario that a woman is about to smack a child (Figure 2a).

\begin{tabular}{|l|l|l|l|}
\hline & \multicolumn{1}{|c|}{ Fun } & \multicolumn{1}{c|}{ Interesting } & \multicolumn{1}{c|}{ Easy } \\
\hline Park & $4.06(1.07)$ & $3.96(1.06)$ & $4.06(1.06)$ \\
\hline School & $4.06(1.11)$ & $3.99(1.06)$ & $4.04(1.06)$ \\
\hline Friend's home & $4.10(1.1)$ & $4.11(1.04)$ & $4.12(10.06)$ \\
\hline Shop & $4.05(1.25)$ & $4.05(1.25)$ & $4.18(1.04)$ \\
\hline
\end{tabular}

Table 3. An overview of mean ratings (standard deviation) of the three evaluative constructs for the four micro-worlds. The range of $N$ : 567 - 605 (missing data: $3 \%$ - 9\%)

There are significant correlations between the three evaluative constructs within individual micro-worlds (range: $r=.09-.65$ ) and across the micro-worlds (range: $r=.08$ to $.52)$. Given the higher $\mathrm{N}$, these significant values are not particularly exciting. However, there were significant gender differences in three of the 12 ratings (Table 4) where girls found the micro-world School more fun and interesting than boys did; the same trend was observed for the perceived interestingness of Home.

\begin{tabular}{|l|l|l|l|}
\hline & \multicolumn{1}{|c|}{$\begin{array}{c}\text { Fun in } \\
\text { School }\end{array}$} & $\begin{array}{l}\text { Interesting in } \\
\text { School }\end{array}$ & $\begin{array}{l}\text { Interesting in } \\
\text { Home }\end{array}$ \\
\hline \multirow{2}{*}{ Boy } & $\begin{array}{l}3.96(1.17) \\
\mathrm{n}=276\end{array}$ & $\begin{array}{l}3.85(1.13) \\
\mathrm{n}=275\end{array}$ & $\begin{array}{l}3.99(1.08) \\
\mathrm{n}=273\end{array}$ \\
\hline \multirow{2}{*}{ Girl } & $\begin{array}{l}4.16(1.05) \\
\mathrm{n}=310\end{array}$ & $\begin{array}{l}4.12(0.97) \\
\mathrm{n}=314\end{array}$ & $\begin{array}{l}4.21(.98) \\
\mathrm{n}=318\end{array}$ \\
\hline Statistics & $t_{(584)}=-2.23 *$ & $t_{(587)}=-3.16^{* *}$ & $t_{(589)}=-2.53 *$ \\
\hline
\end{tabular}

Table 4. Gender significant differences in three ratings: Mean (SD) $(* p<.05, * * p<.01)$

Apart from Gender, the variable Deprivation Level had some significant influences in the children's perceived ease of playing in the micro-world School and Home (Table 5).

\begin{tabular}{|c|c|c|c|}
\hline & Level 1 & Level 2 & Level 3 \\
\hline Easy in & $4.14(1.06)$ & $4.15(0.97)$ & $3.84(1.14)$ \\
School & $\mathrm{n}=210$ & $\mathrm{n}=172$ & $\mathrm{n}=193$ \\
\hline Easy in Home & $4.25(1.03)$ & $4.05(1.08)$ & $4.04(1.06)$ \\
& $\mathrm{n}=213$ & $\mathrm{n}=174$ & $\mathrm{n}=195$ \\
\hline
\end{tabular}

Table 5. Children's ratings per Deprivation Level $(1,2,3)$ for Easy in School and Home: Mean (SD). Level 1 = least deprived; Level 3 = most deprived

For the dimension 'easy' in School, there are highly significant differences between Level 1 and Level $3\left(t_{(401)}=\right.$ $2.77, p<.01)$ and between Level 2 and Level $3\left(t_{(363)}=2.78\right.$, $p<.01)$. For the dimension 'easy' in Home, the only significant difference is between Level 1 and Level $3\left(t_{(406)}=\right.$ $2.01, p<.05)$. The higher the level, the more deprived a school is. Hence, it can be inferred that the children coming from higher income families tended to find it easier to deal with the scenarios in Home and School.

\section{Four micro-worlds: Qualitative data}

As explained earlier, the rich qualitative data of in-game dialogues can reveal the children's awareness of the law in their everyday lives. However, in this paper we do not delve into this aspect as it is highly domain-specific; the data analysis entails a very elaborate law-based coding scheme.

In contrast, a relatively light-weight coding scheme can be applied to the children's rather simple and short written responses (Table 6) to the four open-ended questions "Visiting the <Park/School/Shop/Friend's home> made me want to find out more about ..." in the post-game evaluation. The questions could be less exciting for the children as they had already been exposed to the scenarios, though they could still be stimulated to think more about the implications of the scenarios. The shortness of the answers might be attributed to the children's writing ability. Results of a repeatedmeasures ANOVA indicate that the differences in the length across the four micro-worlds are statistically significant $\left(\mathrm{F}_{(3,623)}=24.32, p<.001\right)$. This can be attributed to the order effect; the children might be bored when they were evaluating the fourth micro-world (i.e. Shop). Logistically it would be difficult to randomize the order of the scenarios in the paper-based questionnaire.

\begin{tabular}{|l|l|l|l|l|}
\hline Length & Park & School & Friend's & Shop \\
\hline Mean & 49.6 & 46.3 & 40.8 & 37.4 \\
\hline SD & 30.3 & 29.2 & 27.0 & 27.7 \\
\hline N & 596 & 578 & 572 & 551 \\
\hline Range & $3-201$ & $3-172$ & $3-163$ & $3-169$ \\
\hline
\end{tabular}

Table 6. Length (in characters) of written responses to the

four open-ended questions in the post-game evaluation.

We analysed the written responses along two dimensions: First, the scope of the response, which can be categorized as within or beyond the given scenarios:

- within: The scope of the response is closely related to the object(s) or storyline of the scenarios, including a plain description of what is already presented ("the broken slide"), enquiry for more information ("why the mum smacked the child"), and empathizing more with the scenario ("learn more about how would it feels about if someone broke my scooter");

- outside: The scope of the response extends beyond the scenarios to raise concerns/queries or give comments with different levels of concreteness. Examples are instance: "about the game creation", "responsibility of my own property and shared property", "Do adults have more rights than children?", "how to make more friends in the world", "the law and the government"; "why didn't the shop have security system?"

Second, the type of information addressed in the response, which can be categorized with the self-explanatory question words used by the children (i.e. what, how, why, whether, who), with their suggested action or with their general concept/comment. Examples are given below to illustrate these categories:

- what: "What's not fair and what is?", "What bad things happen in parks on a regular basis?”, “What dangers there are of being home alone?" 
- how: "How the council take care of broken equipment like the swings or the slide", "How the school could be if the teachers do not bother or are not responsible?", "How people try to trick kids and how people are actually lying for money?"

- why: "Why this game was made?", "Why the trip was only for boy?", "Why was there a snail in the drink and why the shop man didn't give the change back?"

- whether: "Whether an adult is allowed to hit a child?", "if it should be illegal to be sexist or not?"

- who: "Who broke the public things in the park?", "Who was sending the boy horrid messages?", "Who was in charge of the school?"

- suggest action: "Doing your rights understanding to stand up for what you believe in", "Get the kids opinion about new school uniform", "You should always tell an adult when you're getting bullied", "Checking something before buying it"

- general concept/comment: "the law and what is right and what is wrong", "school laws and consequences", "It also gives us an outlook to the school and fairness given out to each pupil in school", "parents responsibility for their kids"

As shown in Table 7, there are differences among the four micro-worlds in the children's intentions to know more about the concrete scenarios or about general queries, which are presumably abstracted from their experiences of the respective micro-world. For instance, in the case of Park, $40 \%$ of the responses are 'outside', as compared with $19 \%$ in the case of Friend's Home. Results of the non-parametric Friedman test show that the differences are statistically significant $\left(\chi^{2}(3,605)=58.39, p<.01\right)$.

To illustrate their qualitative differences, $9 \%$ and $2.4 \%$ of the responses in Park and Friend's home respectively mention the word "law(s)". In each of the micro-worlds, there is a focal concern aroused by a specific scenario: physical chastisement in Park, gender equity in School (most of the "why" questions), age for home alone in Friend's Home (most of the "what" questions) and stealing in Shop (most of the "why" questions).

\begin{tabular}{|l|c|c|c|c|}
\hline Scope & Park & School & Friend's & Shop \\
\hline Within & $53 \%$ & $57 \%$ & $72 \%$ & $60 \%$ \\
\hline Outside & $40 \%$ & $33 \%$ & $19 \%$ & $27 \%$ \\
\hline n/a* & $7 \%$ & $10 \%$ & $9 \%$ & $13 \%$ \\
\hline
\end{tabular}

$* \mathrm{n} / \mathrm{a}$ : the responses are either missing or illegible

Table 7. Scopes of the children's responses in the micro-worlds

\begin{tabular}{|l|l|l|l|l|}
\hline Type & Park & School & Friend's & Shop \\
\hline What & $21 \%$ & $11 \%$ & $26 \%$ & $15 \%$ \\
\hline How & $14 \%$ & $5 \%$ & $4 \%$ & $7 \%$ \\
\hline Why & $13 \%$ & $20 \%$ & $15 \%$ & $18 \%$ \\
\hline Whether & $4 \%$ & $5 \%$ & $4 \%$ & $4 \%$ \\
\hline Who & $5 \%$ & $6 \%$ & $2 \%$ & $3 \%$ \\
\hline Action & $4 \%$ & $1 \%$ & $4 \%$ & $7 \%$ \\
\hline General & $39 \%$ & $52 \%$ & $45 \%$ & $46 \%$ \\
\hline
\end{tabular}

Table 8: Types of information that the children wanted to know more about the micro-worlds.
Furthermore, the responses in the "within" category are mostly presented with the question words listed in Table 8. For instance, in Park most of "why" questions are about the scenario where the woman was about to smack the child. $19.8 \%$ of all the responses mention this scenario. It indicates that the question "Are any of these adults allowed to hit children?" (Figure $2 \mathrm{a} \& 2 \mathrm{~b}$ ) has stimulated the children to reflect on the issue (the term 'child abuse' is mentioned 12 times).

Five game features

With regard to the five game features, all were positively rated in general (Table 9). Building an alien pet was most favoured by the children, followed by the game characters, Rex and Lex.

\begin{tabular}{|c|c|c|c|c|c|}
\hline & Lex & Rex & $\begin{array}{c}\text { Build } \\
\text { pet }\end{array}$ & $\begin{array}{c}\text { Spin } \\
\text { wheel }\end{array}$ & $\begin{array}{c}\text { Record } \\
\text { voice }\end{array}$ \\
\hline Mean & 4.66 & 4.67 & 4.77 & 4.05 & 4.28 \\
\hline SD & 0.74 & 0.72 & 0.59 & 1.05 & 1.08 \\
\hline
\end{tabular}

Table 9. An overview of mean ratings ad standard deviation (SD) of the five game features

There are highly significant gender and year-group differences in the fondness for Lex (Gender: $t_{(596)}=3.196$, $p<.01$; Year: $\left.\mathrm{t}_{(315)}=4.05, p<.001\right)$. Girls $\left(\mathrm{M}_{\text {girl }}=4.75, \mathrm{SD}_{\text {girl }}\right.$ $\left.=0.61, \mathrm{~N}_{\text {girl }}=320\right)$ tended to like Lex more than boys did; $\left(\mathrm{M}_{\text {boy }}=4.56, \mathrm{SD}_{\text {boy }}=0.86, \mathrm{~N}_{\text {boy }}=278\right)$. Year $4\left(\mathrm{M}_{\text {year } 4}=4.78\right.$, $\left.\mathrm{SD}_{\text {year } 4}=0.57, \mathrm{~N}_{\text {year} 4}=213\right)$ tended to like Lex more than their Year 6 counterparts $\left(\mathrm{M}_{\text {year6 }}=4.44, \mathrm{SD}_{\text {year6 }}=0.9, \mathrm{~N}_{\text {year6 }}=\right.$ 104). The contrasts can be illustrated by some qualitative comments "Lex has an annoying voice" (Boy, Year 5, rating: 1); "It was so fun Lex was so cute" (Girl, Year 5, rating: 5).

One of the gamification features for engaging the children to share their thoughts is the possibility to record their voices. Interestingly, there is a significant gender difference in the perceived enjoyability of this feature $\left(\mathrm{t}_{(598)}=2.43, p<.05\right)$. Girls $\left(\mathrm{M}_{\text {girl }}=4.38, \mathrm{SD}_{\text {girl }}=0.98, \mathrm{~N}_{\text {girl }}=320\right)$ tended to enjoyed the voice recording more than boys $\operatorname{did}\left(\mathrm{M}_{\mathrm{boy}}=4.17\right.$, $\left.\mathrm{SD}_{\text {boy }}=1.17, \mathrm{~N}_{\text {boy }}=280\right)$. Some qualitative comments can illustrate the contrasts:

- "I found the game fun and it is cool to record your own voice, it's like actually speaking to Lex" (Girl, Year 6, rating: 5)

- "it was a fun game but yet I wasn't comfortable about recording my voice" (Boy, Year 6, rating: 2)

- "I thought that recording a voice is good but it could have been typed" (Girl, Year 5, rating: 3)

- "don't putting recording your voice" (Boy, Year 4, rating: 1)

- "I like the way you've put the recording the voice" (Girl, Year 4, rating: 5)

\section{GENERAL DISCUSSION}

Gamification work is still at its nascent stage with different levels of enthusiasm, expectation, skepticism, optimism and pessimism from both the academic and industrial worlds [1, 3]. The debates of what gamification is and is not have even 
led to some pioneering researchers in this area (cf. [1]) to drop the notion of gamification, replacing it with a more design-oriented term "gameful design"[1]. Despite the meticulous effort to differentiate wholes versus elements and paidia (free exploratory play) versus ludus (rule-based play) (for details see [1]), the boundaries between games and gamification remain blurred. Nevertheless, it is crucial to clarify some misconceptions about gamification. As Kapp [3] remarks, gamification is not just about leaderboard, badges or scores. Nor is it a term used to trivialize the activities such as learning and research that gamification is deployed to support. In fact, we argue that designing gamified research tools can be more challenging than designing the traditional ones, but the outcome in terms of the quality of empirical data could be more beneficial than otherwise. However, in the context of LICL, such expected benefits cannot be demonstrated as there are no control studies.

To reiterate our main research goal as specified in Introduction: We aim to address the theoretical and practical concerns in the area of gamification. What we want to emphasize is that while the area of gamification is still dealing with the definitional issue and thus its unique identity in the research community at large, it is critical that the gamification work is grounded in sound, established theories. Given that UX focuses on users' lived experiences with interactive technologies, especially emotional and affective responses which are particularly relevant to gameplay, we argue for applying UX theoretical frameworks $[4,6,32]$ to inform and guide the design and evaluation of gamified research tools. The work of the project LICL as described above can illustrate well the realization of this endeavour. Indeed, the evaluative findings suggest that the UX theories-informed gamified research tool can lead to the desirable qualities as perceived by the participating children: fun or pleasure (hedonic quality), ease-of-use as a critical aspect of usability (pragmatic quality), and interestingness or attractiveness (aesthetic quality).

Apart from the importance of theories, we argue that methodologically, it may not be adequate to rely solely on a gamified research tool for data collection. This is especially relevant when a game is linked to a domain, it is essential to synthesize different perspectives and expertise in game design and domain-specific knowledge. A mixed-method approach integrating the strengths of the traditional and gamified research techniques and tools is required. This can help triangulate empirical findings as well.

Similar to the traditional research methods and tools, selecting representative samples for a gamified research study is critical for the validity and reliability of empirical data. Nonetheless, as games, despite their popularity, are not to everybody's liking, assuming that gamified research works regardless of individual preferences can compromise the quality of empirical findings. Developing a gamified research tool involves a number of design decisions (e.g., 2D vs. 3D graphics), which are relevant to entertainment games as well. However, a particular challenge of developing a gamified research tool is to strike a balance between gaming and directing a player's focus onto the topic in question. In other words, the game elements should not be too prominent or engaging lest they would distract the player from the main tasks.

Like all research studies involving human participants, in developing and deploying a gamified research tool, potential ethical and moral issues need to be taken into serious consideration. In particular, the playful guise of the game may prompt the research participants to share unwittingly more than they otherwise would. To safeguard against this potential risk of manipulation, all participants (children, parents/carers) and stakeholders (teachers) must be wellinformed about the purpose of the gamified research tool, the goal of the overall study, and their participation rights. Consent forms, written in a jargon-free and easy language, must be understood and signed by the participants. In LICL, individual legal scenarios have been debriefed shortly after the gameplay session.

\section{CONCLUSION}

Three major challenges we have tackled in the course of developing the gamified research tool are: (i) to ground the design and evaluation work in sound theoretical frameworks; (ii) to identify the relevant and engaging real-life scenarios; (iii) to ensure the usability and utility of the game. The corresponding resolutions are the two established UX frameworks, the child-centred participatory design and pilot study, and the close communication between the academic team and the game company.

Whether the gamified research tool would be more costeffective than the traditional surveys and interviews remains an empirical question to be answered. Some rigorous random control studies need to be conducted; it is foreseen that a number of methodological challenges need to be addressed to ensure that findings are comparable. Another future work is to translate the insights gained from the project LICL into a digital educational game (DEG) that aims to enhance children's understanding of the law in their everyday lives. This DEG so developed is anticipated to have significant societal impact.

\section{SELECTION AND PARTICIPATION OF CHILDREN}

634 children aged 7-11 from eight state schools in the UK were recruited. The field studies were approved by the Research Ethics committee of the University of Leicester. It was clearly specified which data would be collected from the participants under their consent and how the data would be anonymized as well as securely stored in encrypted devices. Consent forms completed by parents/carers and children themselves were in line with the ethical guidelines of British Research Education Association. All children were explicitly informed that they could withdraw from the research at any time. 


\section{REFERENCES}

1. Walz, S.P., \& Deterding S. (2014). An introduction to the gameful world. In S.P. Walz \& S. Deterding (Eds.), the Gameful World: Approaches, issues and applications (pp. 1-13). MIT Press.

2. Deterding, S., Dixon, D., Khaled, R., \& Nacke, L. (2011). From game design elements to gamefulness: defining gamification. In Proceedings of the 15th International Academic MindTrek Conference: Envisioning Future Media Environments (pp. 9-15). ACM.

3. Kapp, K. M. (2012). The gamification of learning and instruction: game-based methods and strategies for training and education. John Wiley \& Sons.

4. Hassenzahl, M. (2004). The interplay of beauty, goodness, and usability in interactive products. Human-Computer Interaction, 19(4), 319-349.

5. Hassenzahl, M. (2010). Experience design: Technology for all the right reasons. Synthesis Lectures on HumanCentered Informatics, 3(1), 1-95.

6. McCarthy, J., \& Wright, P. (2004). Technology as experience. MIT Press.

7. Ramirez, D., \& Squire, K. (2014). Gamification and learning. In S.P. Walz \& S. Deterding (Eds.), the Gameful World: Approaches, issues and applications (pp. 625-652). MIT Press.

8. Munson, S.A., Poole, E., Berry, D., \& Peyton, T. (2014). Gamification and health. In S.P. Walz \& S. Deterding (Eds.), the Gameful World: Approaches, issues and applications (pp. 597-624). MIT Press.

9. Froehlich, J. E. (2014). Gamifying green: Gamification and environmental sustainability. In S.P. Walz \& S. Deterding (Eds.), the Gameful World: Approaches, issues and applications (pp. 563-596). MIT Press.

10. Kumar, J. (2013). Gamification at work: Designing engaging business software (pp. 528-537). Springer Berlin Heidelberg.

11. Kuo, M. S., \& Chuang, T. Y. (2016). How gamification motivates visits and engagement for online academic dissemination-An empirical study. Computers in Human Behavior, 55, 16-27.

12. Prensky, M. R. (2012). From digital natives to digital wisdom: Hopeful essays for 21 st century learning. Corwin Press.

13. Gee, J. P. (2003). What videogames have to teach us about learning and literacy. Palgrave Macmillan

14. Squire, K. (2003). Video games in education. Int. J. Intell. Games \& Simulation, 2(1), 49-62.

15. Law, E. L. C., \& Sun, X. (2012). Evaluating user experience of adaptive digital educational games with Activity Theory. International Journal of HumanComputer Studies, 70(7), 478-497.
16. Hamari, J., Koivisto, J., \& Sarsa, H. (2014). Does gamification work?--a literature review of empirical studies on gamification. In System Sciences (HICSS), 2014 47th Hawaii International Conference on (pp. 3025-3034). IEEE.

17. Medina, J. A., Sanchez, J. J., Garcia-Lopez, E., \& Garcia-Cabot, A. (2014). Learning outcomes using objectives with computer science students.

In Proceedings of the 2014 conference on Innovation \& technology in computer science education (pp. 339339). ACM.

18. Su, C. H., \& Su, P. Y. (2015). Study on 3D Meaningful Mobile Gamification Learning Outcome AssessmentAn Example of Blood Circulation Lesson. In Applied Mechanics and Materials, 764,1395-1399).

19. Anderson, P. E., Turner, C., Dierksheide, J., \& McCauley, R. (2014). An extensible online environment for teaching data science concepts through gamification. In Frontiers in Education Conference (FIE) (pp. 1-8). IEEE.

20. Fisher, R. J. (1993). Social desirability bias and the validity of indirect questioning. Journal of consumer research, 303-315.

21. Sarat, A., \& Kearns, T.R. (1995). Law in everyday life. Michigan: University of Michigan Press.

22. Flin, R., Stevenson, Y., \& Davies, G. (1989). Children's knowledge of court proceedings. British Journal of Psychology, 80, 285-297.

23. Peterson-Badali, M., Abramovitch, R. \& Duda, J. (1997). Young children's legal knowledge and reasoning ability. Canadian Journal of Criminology, 39, 145-170.

24. Powell et al. (2008). Children's perceptions of role of police: a qualitative study. International journal of police science and management, 10 (4), pp. 464-473.

25. Muller, M.J. (2007). Participatory design: The third space in HCI. In J. Jacko and A. Sears (Eds.), Handbook of HCI (2nd Ed.). Erlbaum.

26. Druin, A. (1999). The design of children's technology. San Francisco. Morgan Kaufmann Publishers.

27. Duh, H. B.-L., Yee, S. L. C. Y., Gu, Y. X., \& Chen, V. H.-H. (2010). A narrative-driven design approach for casual games with children. In Proceedings of the 5th ACM SIGGRAPH Symposium on Video Games, Los Angeles, California.

28. Tan, J. L., Goh, D. H.-L., Ang, R. P., \& Huan, V. S. (2011). Child-centered interaction in the design of a game for social skills intervention. Comput. Entertain., 9(1), 1-17. doi: 10.1145/1953005.1953007

29. Markopoulos, P., Read, J. M., MacFarlane, S., \& Hoysniemi, J. (2008). Evaluating Children's Interactive 
Products: Principles and Practices for Interaction Designers. Morgan Kaufmann.

30. Brandt, E. (2006, August). Designing exploratory design games: a framework for participation in participatory design? In Proceedings of the ninth conference on Participatory design: Expanding boundaries in design-Volume 1 (pp. 57-66). ACM.

31. Partala, T., \& Kallinen, A. (2012). Understanding the most satisfying and unsatisfying user experiences: Emotions, psychological needs, and context.Interacting with computers, 24(1), 25-34.

32. Law, E. L. C., Hassenzahl, M., Karapanos, E., Obrist, M., \& Roto, V. (2014). Tracing links between UX frameworks and design practices: dual carriageway. In Proceedings of HCI Korea (pp. 188-195). Hanbit Media, Inc.

33. Katz, J. E., \& Sugiyama, S. (2005). Mobile phones as fashion statements: The co-creation of mobile communication's public meaning. In Mobile communications (pp. 63-81). Springer London. ACM.

34. Juul, J. (2008). The magic circle and the puzzle piece. In Gunzel et al (eds.), Conference proceedings of the philosophy of computer games. Potsdam University Press.

35. Calleja, G. (2012). Ludic identities and the magic circle. In: Frissens et al (eds.), Homo Ludens 2.0: Play, Media and Identity. Amsterdam University Press.

36. Salen, K. and Zimmerman, E. (2004). Rules of Play: Game Design Fundamentals. MIT Press.
37. Bogost, J. (2014). Why gamification is bullshit. In In S.P. Walz \& S. Deterding (Eds.), the Gameful World: Approaches, issues and applications (pp. 65-80). MIT Press.

38. Abt, C. C. (1970). Serious games. New Yorks Viking.

39. Raybourn, E. M. (2007). Applying simulation experience design methods to creating serious gamebased adaptive training systems. Interacting with Computers, 19(2):206-214.

40. Barbosa, A. F. and Silva, F. G. (2011). Serious games: design and development of oxyblood. In Proceedings of the 8th International Conference on Advances in Computer Entertainment Technology, page 15. ACM.

41. Heintz, S., \& Law, E. (2015). Game ElementsAttributes Model: a First Step towards a Structured Comparison of Educational Games. In Proc. DiGRA.

42. Read., J., \& Fine, K. (2005). Using survey methods for design and evaluation in child computer interaction. Paper presented at the Workshop on Child Computer Interaction: Methodological Research at INTERACT.

43. Couper, M. P., Tourangeau, R., Conrad, F. G., \& Singer, E. (2006). Evaluating the effectiveness of visual analog scales a web experiment. Social Science Computer Review, 24(2), 227-245.

44. Read., J., \& MacFarlane, S. (2006). Using the fun toolkit and other survey methods to gather opinions in child computer interaction. Paper presented at the Proceedings of the 2006 conference on Interaction design and children, Tampere, Finland. 